\title{
Robust STATCOM control for the stabilisation of fixed-speed wind turbines during low voltages
}

\author{
M. J. Hossain ${ }^{\mathrm{a}, *}$, H. R. Pota ${ }^{\mathrm{a}}$, R. A. Ramos ${ }^{\mathrm{b}}$ \\ ${ }^{a}$ School of Engineering and IT, UNSW@ADFA, Northcott Drive, Canberra, ACT-2600, Australia. \\ ${ }^{b}$ Dept. of Electrical Engg., Engineering School of São Carlos, Av. Trabalhador Sãocarlense, 400 \\ 13566-590-São Carlos-SP, Brazil.
}

\begin{abstract}
This paper presents a robust voltage control scheme for fixed-speed wind generators using a static synchronous compensator (STATCOM) controller. To enable a linear and robust control framework with structured uncertainty, the overall system is represented by a linear part plus a nonlinear part that covers an operating range of interest required to ensure stability during severe low voltages. The proposed methodology is flexible and readily applicable to larger wind farms of different configurations. The performance of the control strategy is demonstrated on a two area test system. Large disturbance simulations demonstrate that the proposed controller enhances voltage stability as well as transient stability of induction generators during low voltage ride through (LVRT) transients and thus enhances the LVRT capability.
\end{abstract}

Keywords: Dynamic voltage stability, Nonlinearity, Linearisation, STATCOM, Robust Control.

\footnotetext{
${ }^{*}$ Corresponding author, Phone: +61432155461, Fax:+61 262688443.

Email addresses: m.hossain@adfa.edu.au (M. J. Hossain), h-pota@adfa.edu.au (H. R. Pota), ramos@sel.eesc.usp.br (R. A. Ramos)
} 


\section{Introduction}

Traditionally, wind power generation has been treated as a distributed small generation or negative load. Wind turbines (WTs) have been allowed to be disconnected when a fault is encountered in a power system. Such a perspective does not, for instance, require wind turbines to participate in voltage and frequency control and their disconnection is considered insignificant in terms of loss of production issues. However, recently, the penetration of wind power is considerably high particularly in some countries such as Denmark (18.5\%), Spain (7.8\%) and Germany (4.3\%) [1]. These figures are equivalent to the annual production of wind power over a total electricity demand. Consequently, the maximum penetration during some peak hours can be 4-5 times these figures [2].

Presently, $30 \%$ of the installed wind power is still being produced by squirrel-cage induction generators (SCIGs) which are directly connected to the grid and operate at an almost fixed speed [3]. They are advantageous as wind generators for their low cost, low maintenance, due to their rugged brushless construction and asynchronous operation. A directly connected induction generator (IG) is not able to contribute to power system regulation and control in the same way as can a conventional field-excited synchronous generator as it needs reactive power support to be connected to stiff grids. However, WTs are usually connected at weak nodes or at distribution levels at which the network was not originally designed to transfer power into the grid [4]. This increases the need for dynamic reactive power support to ridethrough severe faults.

Squirrel cage induction generator consumes reactive power and it slows down voltage restoration after a fault. This can lead into voltage and rotor-speed instability. During a fault, the generator will accelerate due to the imbalance between the mechanical power extracted from the wind and electrical power delivered to the grid. When the voltage is restored after the fault is cleared the generator will consume reactive power, impeding the voltage restoration. When the voltage does not rise quickly enough, the generator continues to accelerate and consumes even larger amount of reactive power. This process may eventually lead to voltage and rotor-speed instability and more so if the wind turbine is connected to a weak grid. To prevent these types of instabilities, advanced and faster STATCOM controllers can be connected to the system [5]. 
Linear control techniques have been predominantly used for controlling a STATCOM. In this approach the system equations are linearised around an operating point. Based on this linearised model, the conventional proportional-integral (PI) controllers are fine tuned to effectively respond to the small scale and large scale disturbances in the power system, where the STATCOM is connected. For instance PI controllers are used in STATCOMs to design internal controllers for distribution which enables them to mitigate voltage flicker [6]. While these models are appropriate for certain small signal applications in the vicinity of a specific steady state operating point, they cannot capture the true nature of the power network and the STATCOM when the system is exposed to large scale faults or dynamic disturbances that change the configuration of the plant to be controlled due to the significantly nonlinear behaviors of the system that occur in the transients after these types of perturbations.

Several methods for controlling the pitch angle have been reported including the PI control method [7], the backstepping method [8], the feedforward method [9] and the adaptive control method [10]. However, these methods do not allow for variations in the parameters and the effect of wind shear for wind turbines. In order to consider variations in parameters and the effect of wind shear, more advanced $H_{\infty}$ control method is considered in [11]. However, the two most important aspects against which a controller should be robust are the changing nature of the operating point and the large deviations from the equilibrium conditions. There is no work reported in the literature which quantifies the deviation of the operating point from the equilibrium point for which the system maintains closed-loop stability. In this paper we provide robustness for this important condition and quantify the stability region around the equilibrium point.

The authors in [12] propose a proportional-integral-derivative (PID) pitch angle controller for a fixed speed active-stall wind turbine. The controller is designed using root-locus method and the nonlinearities of the system are taken into account to determine the second-order transfer functions using step response which represents the system more accurately compared to linear representation. The actual transfer function of the wind turbines is of higher order and the method in [12] cannot capture nonlinearity accurately. To capture the nonlinearity fully, a method using mean-value theorem is proposed in [13] and a excitation controller is designed where unstructured uncertainty representation is presented. This representation is 
simple but conservative.

The STATCOM with a voltage or current source converter is a nonlinear device. The converter model is usually a multi-input multi-output nonlinear system. The difficulty in controlling the converter is mainly due to the nonlinearity. There are several ways of dealing with the nonlinearity. The simplest way is to use two PI controllers to control the DC term and the reactive power separately [14]. However, in these cases, the response time is usually large, and it is difficult to find appropriate PI parameters in a systematic way. Another method is to write the state equations of the system, then linearise the system around an operating point [15]. The problem with this method is that the controller design is dependent on the operating point, which is not adequate in the event of large disturbances.

This paper presents a control method for the STATCOM converter in order to regulate reactive power exchanged between the machine and the grid. A pitch angle controller is also designed using standard technique [16] in order to control active power. The active power is controlled in order to be adapted to the wind speed in a wind energy conversion system and the reactive power control allows to get a unitary power factor between the stator and the grid.

The proposed method can be used to design a linear controller which is robust to accommodate post-fault low-voltage conditions. The extended robustness is provided by the exact linearisation of the nonlinear model using the mean-value and the Cauchy remainder [17]. This reformulation allows us to design a robust controller against structured uncertainty, which refers to the fact that the uncertainty can be broken up into a number of independent uncertainty blocks. The controller performance is evaluated through simulations by applying large disturbances. The comparisons of these results with those obtained from conventional PI-based STATCOM controller [18] reveals the efficacy of the proposed STATCOM control design.

The organisation of the paper is as follows: Section 2 provides the mathematical modelling of the power system devices under consideration, and test system and control task are presented in Section 3. Section 4 describes the linearisation technique and bounding for uncertainties and Section 5 discusses the STATCOM controller design technique. Controller design algorithm and performance of the controller are outlined in Section 6. Section 7 draws 
the conclusion.

\section{Power system model}

The schematic structure of a fixed-speed wind turbine with a SCIG is depicted in Fig. 1 [16]. It is the simplest type of WT technology and has a turbine that converts the kinetic energy of wind into mechanical energy. The generator then transforms the mechanical energy into electrical energy and then delivers the energy directly to the grid.

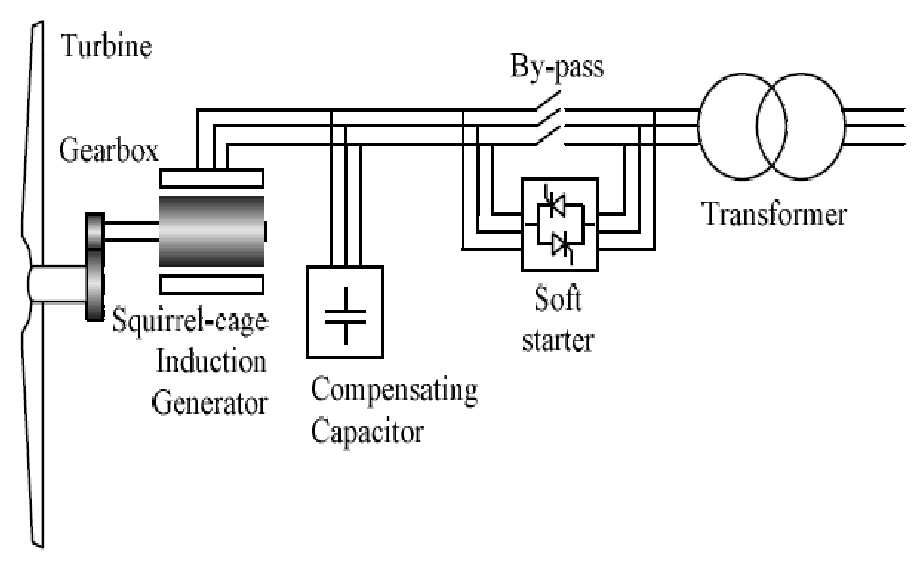

Figure 1: System structure of wind turbine with directly connected squirrel-cage induction generator

The rotor of the wind turbine, with radius $R_{i}$, converts energy from the wind to the rotor shaft, rotating at the speed, $\omega_{m_{i}}$. The power from the wind depends on the wind speed, $V_{w_{i}}$, the air density, $\rho_{i}$, and the swept area, $A_{w t_{i}}$. From the available power in the swept area, the power on the rotor is given based on the power coefficient $c_{p_{i}}\left(\lambda_{i}, \theta_{i}\right)$, which depends on the pitch angle of the blade, $\theta_{i}$, and the ratio between the speed of the blade tip and the wind speed, denoted tip-speed ratio, $\lambda_{i}=\frac{\omega_{m_{i}} R_{i}}{V_{w_{i}}}$. The aerodynamic torque applied to the rotor for the $i^{\text {th }}$ turbine by the effective wind speed passing through the rotor is given as [19]:

$$
T_{a e_{i}}=\frac{\rho_{i}}{2 \omega_{m_{i}}} A_{w t_{i}} c_{p_{i}}\left(\lambda_{i}, \theta_{i}\right) V_{w_{i}}^{3}
$$

where $c_{p_{i}}$ is approximated by the following relation [20]:

$$
c_{p_{i}}=\left(0.44-0.0167 \theta_{i}\right) \sin \left[\frac{\pi\left(\lambda_{i}-3\right)}{15-0.3 \theta_{i}}\right]-0.00184\left(\lambda_{i}-3\right) \theta_{i},
$$

where $i=1, \cdots, n, n$ is the number of wind turbines. 
A transient model of a single cage induction generator (IG) is described by the following algebraic-differential equations [19], [21]:

$$
\begin{aligned}
& \dot{s}_{i}=\frac{1}{2 H_{G_{i}}}\left[T_{m_{i}}-T_{e_{i}}\right], \\
& \dot{E}_{q r_{i}}^{\prime}=-\frac{1}{T_{o_{i}}^{\prime}}\left[E_{q r_{i}}^{\prime}-\left(X_{i}-X_{i}^{\prime}\right) i_{d s_{i}}\right]-s_{i} \omega_{s} E_{d r_{i}}^{\prime}, \\
& \dot{E}_{d r_{i}}^{\prime}=-\frac{1}{T_{o_{i}}^{\prime}}\left[E_{d r_{i}}^{\prime}+\left(X_{i}-X_{i}^{\prime}\right) i_{q s_{i}}\right]+s_{i} \omega_{s} E_{q r_{i}}^{\prime}, \\
& V_{d s_{i}}=R_{s_{i}} i_{d s_{i}}-X_{i}^{\prime} i_{q s_{i}}+E_{d r_{i}}^{\prime}, \\
& V_{q s_{i}}=R_{s_{i}} i_{q s_{i}}+X_{i}^{\prime} i_{d s_{i}}+E_{q r_{i}}^{\prime}, \\
& v_{t_{i}}=\sqrt{V_{d s_{i}}^{2}+V_{q s_{i}}^{2}},
\end{aligned}
$$

where $X_{i}^{\prime}=X_{s_{i}}+X_{m_{i}} X_{r_{i}} /\left(X_{m_{i}}+X_{r_{i}}\right)$ is the transient reactance, $X_{i}=X_{s_{i}}+X_{m_{i}}$ the rotor open-circuit reactance, $T_{o_{i}}^{\prime}=\left(L_{r_{i}}+L_{m_{i}}\right) / R_{r_{i}}$ the transient open-circuit time constant, $v_{t_{i}}$ the terminal voltage of the IG, $s_{i}$ the slip, $E_{d r_{i}}^{\prime}$ the direct-axis transient voltages, $E_{q r_{i}}^{\prime}$ the quadrature-axis transient voltages, $V_{d s_{i}}$ the d-axis stator voltage, $V_{q s_{i}}$ the q-axis stator voltage, $T_{m_{i}}$ the mechanical torque, $T_{e_{i}}=E_{d r_{i}} i_{d s_{i}}+E_{q r_{i}} i_{q s_{i}}$, the electrical torque, $X_{s_{i}}$ the stator reactance, $X_{r_{i}}$ is the rotor reactance, $X_{m_{i}}$ the magnetising reactance, $R_{s_{i}}$ the stator resistance, $R_{r_{i}}$ the rotor resistance, $H_{G_{i}}$ the inertia constant of the IG, $i_{d s_{i}}$ and $i_{q s_{i}}$ the d- and q-axis components of the stator current, respectively.

Basic STATCOM circuit consists of a voltage source converter (VSC) and a DC capacitor. The dynamic of this voltage source is governed by the charging and discharging of a large (nonideal) capacitor. The capacitor voltage can be adjusted by controlling the phase angle difference between line voltage $V_{t}$ and $\mathrm{VSC}$ voltage $E$. If the phase angle of line voltage is taken as a reference, the phase angle of VSC voltage is the same as the firing angle $\alpha$ of VSC. Thus, if the firing angles are slightly advanced, the dc voltage $V_{d c}$ decreases, and reactive power flows into STATCOM. Conversely, if the firing angles are slightly delayed, the dc voltage increases and STATCOM supplies reactive power to the bus. By controlling the firing angles of VSC, the reactive power can be generated from or absorbed by STATCOM and thus the voltage regulation can be achieved. The STATCOM model can be described by the following equation:

$$
\dot{v}_{d c}(t)=-\frac{P_{s}}{C v_{d c}}-\frac{v_{d c}}{R_{c} C}
$$




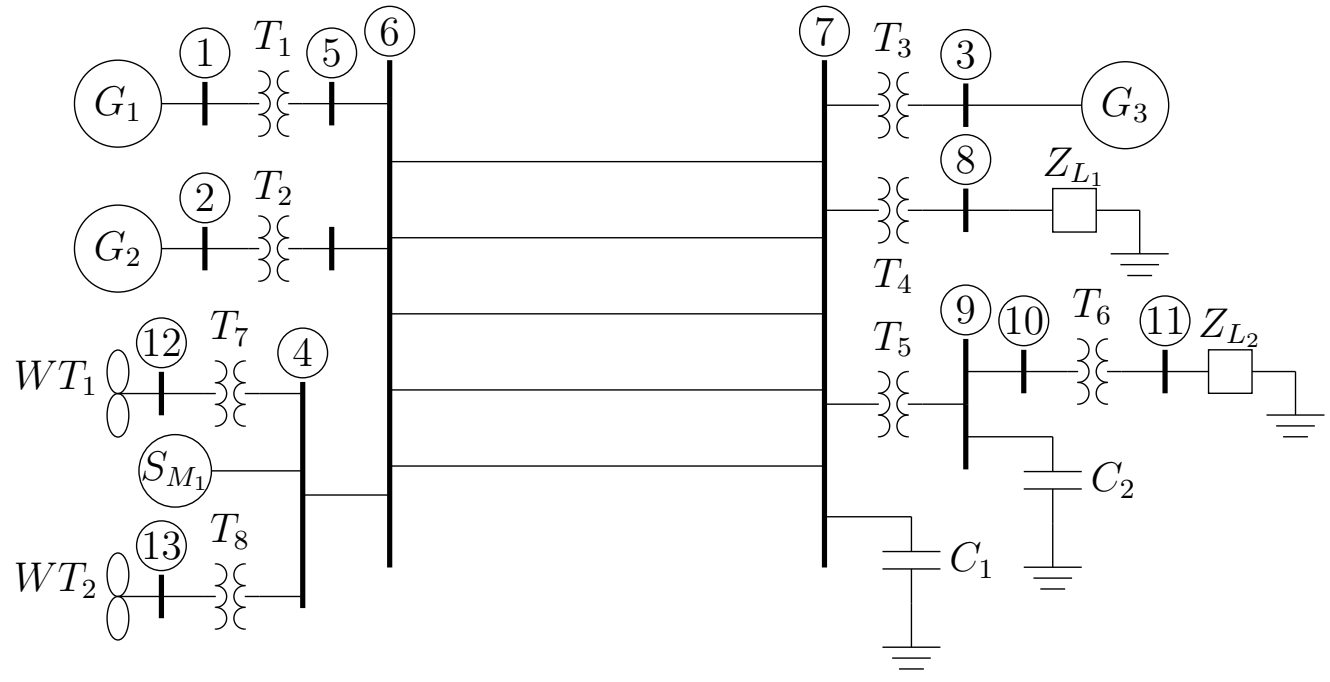

Figure 2: 3 machine 2 area test system (G-synchronous generator, WT-wind generator, S-STATCOM and L-load)

where $v_{d c}$ is the capacitor voltage, $P_{s}$ is the power supplied by the system to the STATCOM to charge the capacitor, which is a nonlinear function of $\left(\alpha, k, E, v_{d c}, E_{q r}^{\prime}, E_{d r}^{\prime}\right.$, and $\left.E=k v_{d c} \angle \alpha\right)$. The control inputs are related to $v_{d c}$ through $P_{s}$. The STATCOM bus voltage measurement system is modelled as a first order system (for constants $T_{m}$ and $K_{m}$ ):

$$
\dot{v}_{t m}=-\frac{v_{t m}}{T_{m}}+K_{m} v_{t}
$$

where $v_{t m}$ is the sensor output and $v_{t}$ is the voltage at Bus 4 . For stability analysis we include the transformer and the transmission line in the reduced admittance matrix.

\section{Test system and control task}

The two area test system shown in Fig. 2 consists of 11 buses and 3 generators [22]. It has an area fed by a remote generator $G_{2}$ with a nominal capacity of 2200 MVA through five $500 \mathrm{kV}$ parallel lines. Generator $\left(G_{1}\right)$ models an infinite bus representing a large-inertia interconnected system.

Area 2 contains a 1600 MVA local synchronous generator $\left(G_{3}\right)$ and two aggregate loads, one industrial served directly via the off-nominal constant ratio transformer $\left(T_{4}\right)$ and the other a commercial-residential load on bus 11. All the load, $P_{L}=6655 \mathrm{MW}$ and $Q_{L}=2021 \mathrm{MVAr}$, for this test system is in area 2 and is connected to the transmission network through two transformers $\left(T_{5}\right.$ and $\left.T_{6}\right)$ and a $115 \mathrm{kV}$ transmission line between buses 9 and 10 . 
Table 1: Participation Factors

\begin{tabular}{|l|c|c|c|c|c|c|}
\hline States & $\triangle s_{1}$ & $\triangle E_{d r 1}^{\prime}$ & $\triangle E_{q r 1}^{\prime}$ & $\triangle s_{2}$ & $\triangle E_{d r 2}^{\prime}$ & $\triangle E_{q r 2}^{\prime}$ \\
\hline Parti. Factor & 0.96 & 0.048 & 1.0 & 0.94 & 0.04 & 0.97 \\
\hline
\end{tabular}

We design a robust STATCOM controller for the modified test system where the generators $G_{2}=0 \mathrm{MW}, G_{3}=0 \mathrm{MW}, W T_{1}=1736 \mathrm{MW}$, and $W T_{2}=1154 \mathrm{MW}$. The remaining power is supplied from $G_{1}$ which is considered in this paper as an infinite bus. A STATCOM is connected at Bus 4 to meet the connection requirements for power system grids. The wind generators are arranged in two parallel lines and we represent each of them by an aggregated wind generator model [23]. To appreciate the nature of the control task, we carry out the modal analysis for the open loop system. The dominant mode for the test system is $-0.105 \pm j 0.71$. The participation vector for the dominant mode is shown in Table 1 . The participation vector indicates that the states $E_{q r 1}^{\prime}, E_{q r 2}^{\prime}, s_{1}$ and $s_{2}$ have the most significant contribution to the dominant mode. The dominant mode is related to both reactive and active power mismatch. The reactive power can be controlled by the designed STATCOM controller and a conventional pitch controller is used to control real power. For the test system, the state vector is $x=\left[s_{1}, E_{d r 1}^{\prime}, E_{q r 1}^{\prime}, s_{2}, E_{d r 2}^{\prime}, E_{q r 2}^{\prime}, v_{d c}, v_{t m}\right]^{T}$.

Fig. 3 depicts the pitch angle controller. In this work the pitch rate limit is set to $8(\mathrm{deg} / \mathrm{s})$, $\theta_{\min }=-5^{\circ}, \theta_{\max }=45^{\circ}, \dot{\theta}_{\min }=-10(\mathrm{deg} / \mathrm{s}), \dot{\theta}_{\max }=10(\mathrm{deg} / \mathrm{s})$ and time constant is $0.2 \mathrm{~s}$. In this case, the gain of the tuned (trial and error method) PI controller is obtained as $K_{P}=5$ and $K_{I}=25$.

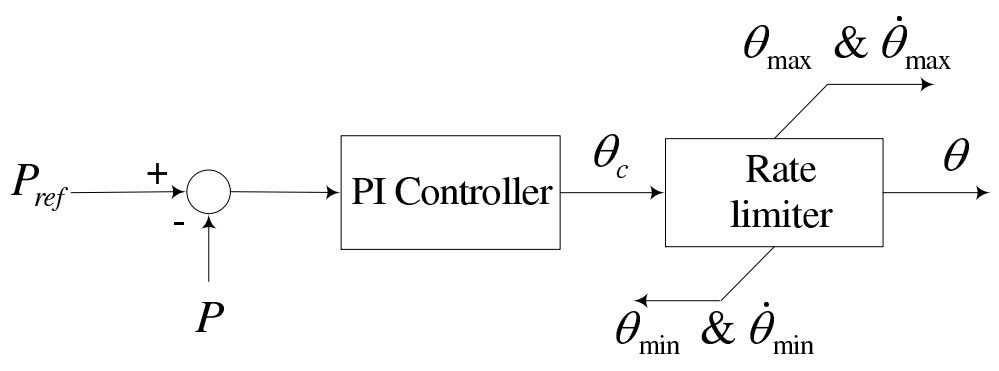

Figure 3: Pitch angle control strategy.

\subsection{STATCOM control strategy}

STATCOM employment has to counteract the well known instability problems related to the induction generator operation conditions, by providing a controlled reactive power, with 


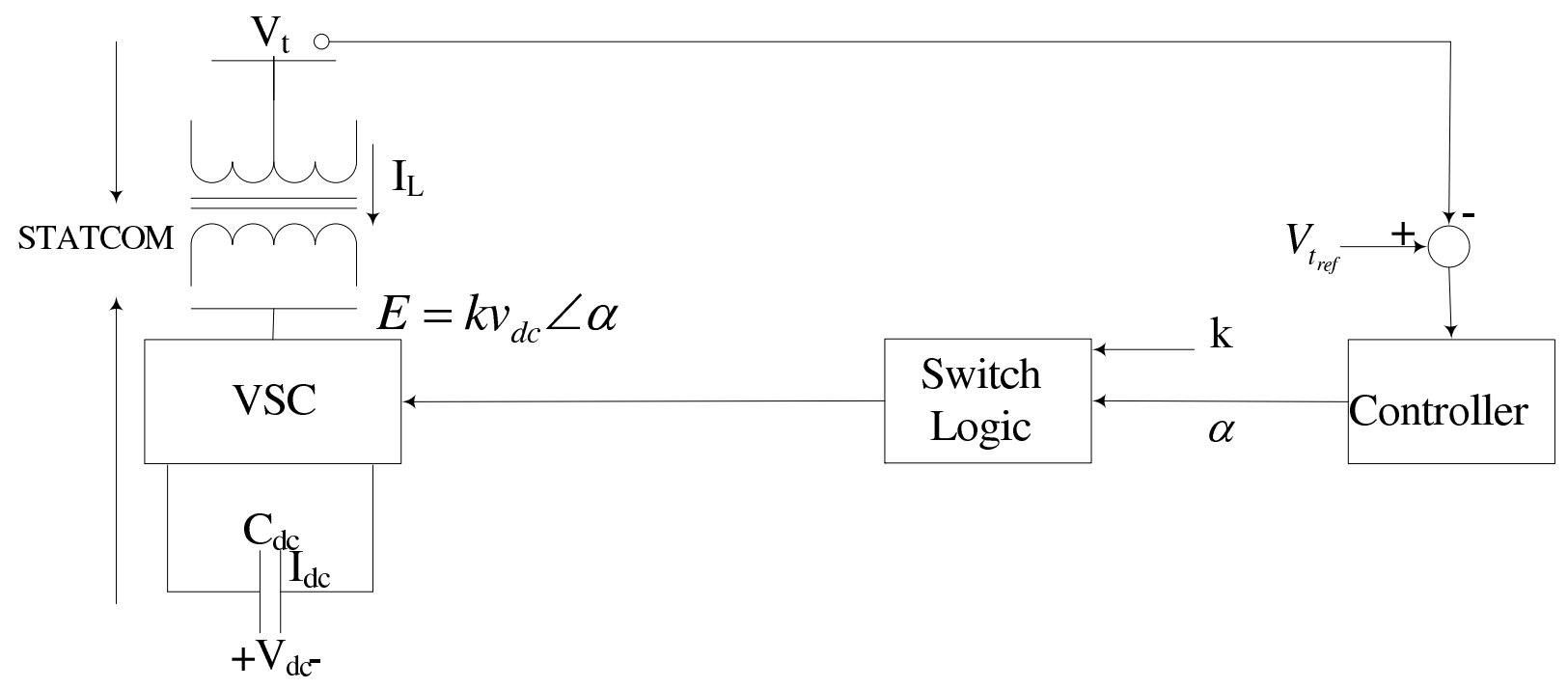

Figure 4: STATCOM control strategy.

the consequent stability margin improvement. The rationale of the proposed control strategy is based upon the ability of the inverter to distribute electrical power between the induction generator and load, guaranteeing the load required voltage profile. More specifically, at steady state conditions, the inverter does not exchange active power with the load, so that only the induction generator supplies the active power amount required by the load and inverter losses.

The STATCOM control strategy used in this paper is shown in Fig. 4. In this method, the compensation is achieved by measuring the rms voltage at PCC. The output voltage $(E)$ magnitude of the VSC relates to the DC side voltage and is also a function of the phase angle and the modulation ratio of the PWM. In this case $k$ is fixed and $\alpha$ is used as the control variable. The inverter control consists of regulating the voltage amplitude and the phase delay angle $(\alpha)$ between the emf $E$ and the inverter output voltage $\left(v_{t}\right)$.

\section{Linearisation and uncertainty modelling}

Linear controllers are designed based on the Taylor series approximation around an equilibrium point. This linearisation technique limits the applicability of the linear model to small deviations from the equilibrium point. In general, the range of these small deviations is difficult to quantify. To quantify the neglected higher order terms, we propose the use of a linearisation scheme which retains the contributions of the higher order terms in the form of the Cauchy remainder. In the design of the linear controller, a bound on the Cauchy re- 
mainder is incorporated as an uncertain term thus quantifying the deviations permitted in the linear model.

Let $\left(x_{0}, u_{0}\right)$ be an arbitrary point in the control space, using the mean-value theorem, the test system dynamics can be rewritten as follows [24]:

$$
\dot{x}=f\left(x_{0}, u_{0}\right)+L\left(x-x_{0}\right)+M\left(u-u_{0}\right),
$$

where $L=\left[\left.\frac{\partial f_{1}}{\partial x}\right|_{\substack{x=x^{* 1} \\ u=u * 1}}, \ldots,\left.\frac{\partial f_{8}}{\partial x}\right|_{\substack{x=x^{* 8} \\ u=u * 8}}\right]^{T}, M=\left[\left.\frac{\partial f_{1}}{\partial u}\right|_{\substack{x=x^{* 1} \\ u=u * 1}}, \ldots,\left.\frac{\partial f_{8}}{\partial u}\right|_{\substack{x=x^{* 8} \\ u=u * 8}}\right]^{T}$.

Here $\left(x^{* p}, u^{* p}\right), p=1, \cdots, 8$, denote points lying on the line segment connecting $(x, u)$ and $\left(x_{0}, u_{0}\right)$ and $f=\left[f_{1}, \ldots, f_{8}\right]^{T}$ denotes the vector function on the right-hand side of the vector differential equations. The identity in equation (10) is an exact reformulation of the system. where the first term on the right-hand side represents the model at equilibrium points, the second term presents the nonlinearity, i.e., the higher order terms in Taylor series expansion, and the third term denotes the input of the system. The nonlinearity of the system is captured through the nonlinear dependencies $x^{* p}=\Phi_{p}\left(x, u, x_{0}, u_{0}\right)$ and $u^{* p}=\Psi_{p}\left(x, u, x_{0}, u_{0}\right), \quad p=$ $1, \ldots, 8$.

Letting $\left(x_{0}, u_{0}\right)$ be the equilibrium point about which the trajectory is to be stabilised and defining $\Delta x \triangleq x-x_{0}, \Delta u \triangleq u-u_{0}$, it is possible to rewrite (10) as follows:

$$
\begin{aligned}
\Delta \dot{x} & =\dot{x}-\dot{x_{0}}=L\left(x-x_{0}\right)+M\left(u-u_{0}\right), \\
& =A \triangle x+(L-A) \triangle x+B_{1} \triangle u+\left(M-B_{1}\right) \triangle u
\end{aligned}
$$

where $A=\left.\frac{\partial f}{\partial x}\right|_{\substack{x=x_{0} \\ u=u_{0}}}$ and $B_{1}=\left.\frac{\partial f}{\partial u}\right|_{\substack{x=x_{0} \\ u=u_{0}}}$.

We rewrite system (11) in terms of the block diagram shown in Fig. 5, where

$$
(L-A) \triangle x+\left(M-B_{1}\right) \triangle u=\sum_{k=0}^{7} B_{2 k} \xi_{k}(t)
$$

where $\xi_{1}(t), \ldots, \xi_{k}(t)$ are known as the uncertainty inputs. The matrices $\left[B_{20}, \cdots, B_{27}\right]$, $\left[\tilde{C}_{10}, \cdots, \tilde{C}_{27}\right]$ are calculated such that

$$
(L-A) \triangle x+\left(M-B_{1}\right) \triangle u=\sum_{k=0}^{7} B_{2 k} \tilde{\phi}_{k}\left(\tilde{C}_{1 k} \triangle x\right)+\sum_{k=0}^{7} B_{2 k} \tilde{\psi}_{k}\left(\tilde{D}_{1 k} \triangle u\right)
$$




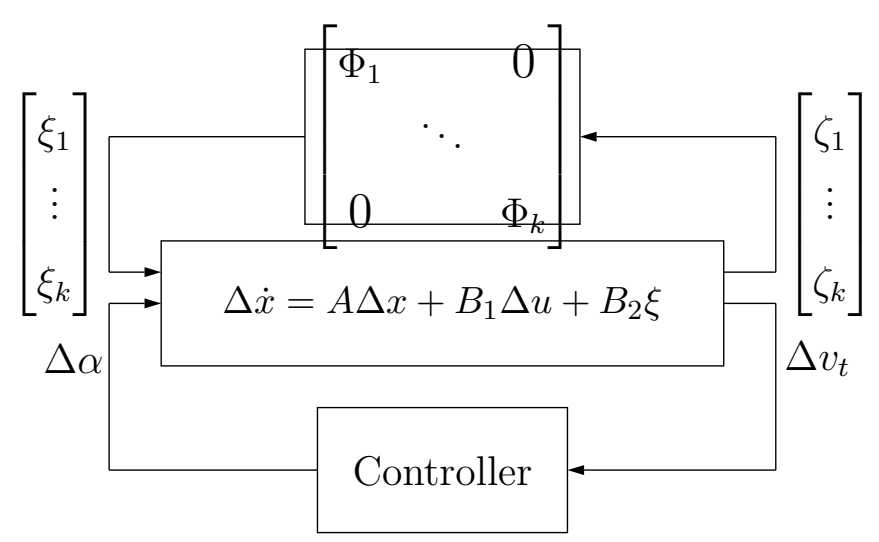

Figure 5: Control strategy of structured uncertain system

where $\xi_{k}=\tilde{\phi}_{k} \tilde{C}_{1 k} \triangle x+\tilde{\psi}_{k} \tilde{D}_{1 k} \triangle u, k=0, \ldots, 7$, and

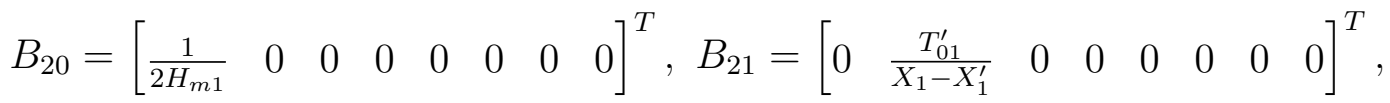

$$
\begin{aligned}
& B_{22}=\left[\begin{array}{llllllll}
0 & 0 & \frac{T_{01}^{\prime}}{X_{1}-X_{1}^{\prime}} & 0 & 0 & 0 & 0 & 0
\end{array}\right]^{T}, B_{23}=\left[\begin{array}{llllllll}
0 & 0 & 0 & \frac{1}{2 H_{m 2}} & 0 & 0 & 0 & 0
\end{array}\right]^{T} \text {, } \\
& B_{24}=\left[\begin{array}{llllllll}
0 & 0 & 0 & 0 & \frac{T_{02}^{\prime}}{X_{2}-X_{2}^{\prime}} & 0 & 0 & 0
\end{array}\right]^{T}, B_{25}=\left[\begin{array}{llllllll}
0 & 0 & 0 & 0 & 0 & \frac{T_{02}^{\prime}}{X_{2}-X_{2}^{\prime}} & 0 & 0
\end{array}\right]^{T} \text {, } \\
& B_{26}=\left[\begin{array}{llllllll}
0 & 0 & 0 & 0 & 0 & 0 & \frac{1}{T o 1} & 0
\end{array}\right]^{T}, B_{27}=\left[\begin{array}{llllllll}
0 & 0 & 0 & 0 & 0 & 0 & 0 & K_{m} X_{s 1}
\end{array}\right]^{T},
\end{aligned}
$$

The nonlinearities considered in this paper are due to the dynamics of $s_{i}, E_{d r_{i}}, E_{q r_{i}}$, and $v_{d c}, i=1,2$, with this the matrices $\tilde{C}_{1 k}$ and $\tilde{D}_{1 k}$ are chosen such that

$$
\tilde{C}_{1 k}=\left[\begin{array}{cccccccc}
1 & 0 & 0 & 0 & 0 & 0 & 0 & 0 \\
0 & 1 & 0 & 0 & 0 & 0 & 0 & 0 \\
0 & 0 & 1 & 0 & 0 & 0 & 0 & 0 \\
0 & 0 & 0 & 1 & 0 & 0 & 0 & 0 \\
0 & 0 & 0 & 0 & 1 & 0 & 0 & 0 \\
0 & 0 & 0 & 0 & 0 & 1 & 0 & 0 \\
0 & 0 & 0 & 0 & 0 & 0 & 1 & 0
\end{array}\right], \tilde{D}_{1 k}=\left[\begin{array}{cccccccc}
1 & 1 & 1 & 1 & 1 & 1 & 1 & 1 \\
1 & 1 & 1 & 1 & 1 & 1 & 1 & 1
\end{array}\right]^{T},
$$

$k=0, \ldots, 7$,

$$
(L-A) \triangle x+\left(M-B_{1}\right) \triangle u=\sum_{k=0}^{7} B_{2 k} \xi_{k}(t)
$$


where $\xi_{k}=\tilde{\phi}_{k} \tilde{C}_{1 k} \triangle x+\tilde{\psi}_{k} \tilde{D}_{1 k} \triangle u$, and $\phi_{k}(t)=\frac{1}{\sqrt{\beta_{k}}}\left[\tilde{\phi}_{k}(t) \quad \tilde{\psi}_{k}(t)\right]$. where $\beta_{k}$ are scaling factors which affect the magnitude of the uncertain outputs $\zeta_{k}, k=0, \ldots, 7$.

In general, $x^{* p}, p=1, \ldots, 8$, are not known beforehand, it is difficult to obtain the exact value of $(L-A)$ and $\left(M-B_{1}\right)$, but it is possible to obtain a bound on $\tilde{\phi}_{k}$ and $\tilde{\psi}_{k}$ over the operating range and parameter $\beta_{k}$ is chosen to ensure

$$
\left\|\phi_{k}(t)\right\|^{2} \leq 1, k=0, \ldots, 7
$$

From this, we have

$$
\left\|\xi_{k}(t)\right\|^{2} \leq \beta_{k}\left\|\left(\tilde{C}_{1 k} \triangle x+\tilde{D}_{1 k} \triangle u\right)\right\|^{2} .
$$

and we recover the IQC (integral quadratic constraint) [25],

$$
\left\|\xi_{k}(t)\right\|^{2} \leq\left\|\zeta_{k}(t)\right\|^{2}, \quad k=0, \ldots, 7
$$

The expressions for $\tilde{\phi}_{k}(t)$ and $\tilde{\psi}_{k}(t)$ can be determined following the procedure given in [26].

The system can now be written as

$$
\triangle \dot{x}=A \triangle x+B_{1} \triangle u+\sum_{k=0}^{7} B_{2 k} \xi_{k}(t) .
$$

To facilitate control design, the power system model is finally summarised as

$$
\begin{aligned}
\triangle \dot{x}(t) & =A \triangle x(t)+B_{1} \triangle u(t)+\sum_{k=0}^{7} B_{2 k} \xi_{k}(t), \\
y(t) & \left.=C_{2} \triangle x(t)+\sum_{k=0}^{7} D_{2 k} \xi_{k}(t)\right) \\
\zeta_{k}(t) & =C_{1, k} \triangle x(t)+D_{1, k} u(t), \quad k=0, \ldots, 7
\end{aligned}
$$

where $\zeta_{k}, k=0, \ldots, 7$, are known as the uncertainty outputs and $y(t)$ is the measured output.

The output matrix is defined as $C_{2}=[0,0,0,0,0,0,0,1]$. We choose $D_{20}=0.01, D_{21}=$ $0.01, D_{22}=0.01, D_{23}=0.1, D_{24}=0.1, D_{25}=0.01, D_{26}=0.1, D_{27}=0.005$. Equations (20)-(22) provide a new representation of the power system model which contains the linear part, and also another part with higher order terms. The new formulation presented in this section is used to design a robust output feedback STATCOM controller for the nonlinear power system. 


\section{Robust STATCOM control}

The control design problem considered in this paper is of providing a stabilising robust output feedback control algorithm for a system containing structured uncertainty described by a certain IQC (Integral Quadratic Constraint) [25], [27]. The output feedback control method is applied to the uncertain systems of the form shown in Fig. 5.

It is shown in [27] that the linear robust control theory can be applied to (20)-(22) subject to the following constraint:

$$
\int_{0}^{t_{i}}\left\|\xi_{k}(t)\right\|^{2} d t \leq \int_{0}^{t_{i}}\left\|\zeta_{k}(t)\right\|^{2} d t, \forall i \text { and } \forall k=0, \ldots, 7
$$

The necessary and sufficient condition for the absolute stabilisability of the uncertain system (20)-(22) is given in terms of the existence of solution to a pair of parameter dependent algebraic Riccati equations [25]. The Riccati equations under consideration are defined as follows: for given constants $\tau_{1}>0, \ldots, \tau_{7}>0$;

$$
\begin{aligned}
& \left(A-\tilde{B}_{2} \tilde{D}_{2}^{T} \Gamma_{\tau}^{-1} C_{2}\right) Y+Y\left(A-\tilde{B}_{2} \tilde{D}_{2}^{T} \Gamma_{\tau}^{-1} C_{2}\right)^{T}+Y\left(C_{\tau}^{T} C_{\tau}\right. \\
& \left.-C_{2}^{T} \Gamma_{\tau}^{-1} C_{2}\right) Y+\tilde{B}_{2}\left(I-\tilde{D}_{2}^{T} \Gamma_{\tau}^{-1} \tilde{D}_{2}\right) \tilde{B}_{2}^{T}=0, \\
& X\left(A-B_{1} G_{\tau}^{-1} D_{\tau}^{T} C_{\tau}\right)+\left(A-B_{1} G_{\tau}^{-1} D_{\tau}^{T} C_{\tau}\right)^{T} X+C_{\tau}^{T} \\
& \left(I-D_{\tau} G_{\tau}^{-1} D_{\tau}^{T}\right) C_{\tau}+X\left(\tilde{B}_{2} \tilde{B}_{2}^{T}-B_{1} G_{\tau}^{-1} B_{1}^{T}\right) X=0, \\
& C_{\tau}=\left[\begin{array}{c}
C_{10} \\
\sqrt{\tau_{1}} C_{11} \\
\vdots \\
\sqrt{\tau_{7}} C_{17}
\end{array}\right] ; \quad D_{\tau}=\left[\begin{array}{c}
D_{10} \\
\sqrt{\tau_{1}} D_{11} \\
\vdots \\
\sqrt{\tau_{7}} D_{17}
\end{array}\right] ; \\
& \tilde{B}_{2}=\left[\begin{array}{llll}
B_{20} & \frac{1}{\sqrt{\tau_{1}}} B_{21} & \cdots & \sqrt{\tau_{7}} B_{27}
\end{array}\right] ; \quad G_{\tau}=D_{\tau}^{T} D_{\tau} ; \\
& \tilde{D}_{2}=\left[\begin{array}{llll}
D_{20} & \frac{1}{\sqrt{\tau_{1}}} D_{21} & \cdots & \sqrt{\tau_{7}} D_{27}
\end{array}\right] ; \quad \Gamma_{\tau}=\tilde{D}_{2} \tilde{D}_{2}{ }_{2} .
\end{aligned}
$$

The original control problem is to stabilise the uncertain system via the robust control. However, introducing $\tau_{1}, \ldots, \tau_{k}$, the problem of absolutely stabilizing an uncertain system becomes equivalent to an output feedback $H_{\infty}$ control problem, the solution of which is well known [28]. The solutions of the above Riccati equations should satisfy the following conditions to guarantee the closed loop stability: $X>0, Y>0$ and the spectral radius of the matrix $X Y$ is $\rho(X Y)<1$. 
The uncertain system (20)-(22) is required to satisfy the following assumptions. Let matrices $B_{2}, C_{1}, D_{1}, D_{2}, G$ and $\Gamma$ be defined by

$$
\begin{aligned}
& B_{2}=\left[\begin{array}{lll}
B_{20} & \cdots & B_{27}
\end{array}\right] ; \quad D_{2}=\left[\begin{array}{lll}
D_{20} & \cdots & D_{27}
\end{array}\right] ; \\
& C_{1}=\left[\begin{array}{l}
C_{10} \\
\cdots \\
C_{17}
\end{array}\right] ; \quad D_{1}=\left[\begin{array}{c}
D_{10} \\
\cdots \\
D_{17}
\end{array}\right] ; \quad G=\sum_{k=0}^{7} D_{1 k}^{\prime} D_{1 k} ;
\end{aligned}
$$

$\Gamma=\sum_{k=0}^{7} D_{2 k}^{\prime} D_{2 k}$. With the above choice, the pair $\left(A, B_{1}\right)$ is stabilisable, $G>0, \Gamma>0$, the pair $\left(A, C_{2}\right)$ is detectable, the pair $\left(A-B_{1} G^{-1} D_{1}^{\prime} C_{1},\left(I-D_{1} G^{-1} D_{1}^{\prime}\right) C_{1}\right)$ is observable, and the pair $\left(A-B_{2} D_{2}^{\prime} \Gamma^{-1} C_{2}, B_{2}\left(I-D_{2} \Gamma^{-1} D_{2}^{\prime}\right)\right)$ is controllable. The output-feedback controller is [27]:

$$
\begin{aligned}
\dot{x}_{c} & =A_{c} x_{c}(t)+B_{c} y(t), \quad u(t)=C_{c} x_{c}(t), \\
\text { where } \quad A_{c} & =A+B_{1} C_{c}-B_{c} C_{2}+\left(\tilde{B}_{2}-B_{c} \tilde{D}_{2}\right) \tilde{B}_{2}^{\prime} X, \\
B_{c} & =(I-Y X)^{-1}\left(Y \tilde{C}_{2}+\tilde{B}_{2} \tilde{D}_{2}^{\prime}\right) \Gamma_{\tau}^{-1}, \\
C_{c} & =-G_{\tau}^{-1}\left(B_{1}^{\prime} X+D_{\tau}^{\prime} C_{\tau}\right) .
\end{aligned}
$$

\section{Controller design and performance evaluation}

First we carry out several simulations by applying large disturbances to get an estimate the operating region during LVRT transients. The controller is designed in the following way to ensure stability in the operating range of interest:

(i) From the simulations of the faulted system (undergoing a large perturbation during low voltages), obtain the range in variations of all state variables and form a volume, $\Omega$, with corner points given by $\left(x_{0_{p}}-x_{f_{p}}\right)$ and $\left(x_{f_{p}}+x_{0_{p}}\right), p=1, \ldots, 7$, where $2 x_{f_{p}}$ is the largest variation in the $p^{\text {th }}$ state variable about its equilibrium value, $x_{0_{p}}$.

(ii) Obtain $\alpha_{k}^{*}=\max _{x_{i}^{* p} \in \Omega}\left\{\alpha_{k}:\left\|\phi_{k}\right\|^{2}<1|,| \psi_{k} \|^{2}<1\right\}$ to satisfy $(16), k=0, \ldots, 7$; the process to obtain $\Gamma_{i}^{*}$ involves obtaining the maximum value of $\left\|\phi_{k}\right\|$ and $\left\|\Xi_{k}\right\|$ over the operating range of interest.

(iii) Check if there exists a feasible controller with $\alpha_{k}=\alpha_{k}^{*}$, i.e., scalars $\tau_{k}$ exist such that there is a feasible solution to the Riccati equations (24) and (25). 
Table 2: Values of $\alpha_{k}, k=0, \ldots, 7$.

\begin{tabular}{|c|c|c|c|c|c|c|c|}
\hline$\alpha_{0}$ & $\alpha_{1}$ & $\alpha_{2}$ & $\alpha_{3}$ & $\alpha_{4}$ & $\alpha_{5}$ & $\alpha_{6}$ & $\alpha_{7}$ \\
\hline 0.85 & 0.95 & 0.45 & 0.98 & 0.68 & 0.65 & 0.79 & 0.94 \\
\hline
\end{tabular}

(iv) Compare the control region with the operating region required to provide the stability during severe low voltages

(v) If we obtain a feasible controller in the above step, increase the range of the operating region if step (iv) is not satisfied or, if we have arrived at the largest possible range then perform an optimal search over the scalar parameters $\tau_{k}$, to get the optimum performance of the test system. If there is no feasible solution with the chosen $\alpha_{k}=\alpha_{k}^{*}$, reduce the range and go to step (ii).

The process described above enables the selection of the largest range for which a feasible controller is obtained. The equilibrium point for this system is $\left(s_{i 0}=0.013, E_{d r i 0}^{\prime}=0.2186\right.$, $\left.E_{q r i 0}^{\prime}=0.9176, v_{d c 0}=1.3, v_{t m 0}=1\right) \mathrm{pu}, i=1,2$. For the given power system model, we obtain the values of $\beta_{k}$ given in Table 2 for the corner points of $\Omega$ as $\bar{s}_{i}=s_{i 0}+0.45 \mathrm{pu}$, $\underline{\mathrm{s}}_{i}=s_{i 0}-0.45 \mathrm{pu}, \bar{E}_{d r_{i}}^{\prime}=E_{d r_{i 0}}^{\prime}+0.27 \mathrm{pu}, \underline{\mathrm{E}}_{d r_{i}}^{\prime}=E_{d r_{i 0}}^{\prime}-0.27 \mathrm{pu}, \bar{E}_{q r_{i}}^{\prime}=E_{q r_{i 0}}^{\prime}+0.28 \mathrm{pu}$, $\underline{\mathrm{E}}_{q r_{i}}^{\prime}=E_{q r_{i 0}}^{\prime}-0.28 \mathrm{pu}, \bar{v}_{d c}=v_{d c_{0}}+0.35 \mathrm{pu}, \underline{\mathrm{v}}_{d c}=v_{d c_{0}}-0.35 \mathrm{pu}, \bar{v}_{t m}=v_{t m_{0}}+0.45 \mathrm{pu}$, $\underline{\mathrm{v}}_{t m}=v_{t m_{0}}-0.45 \mathrm{pu}, \bar{\alpha}=\alpha_{0}+25^{\circ}$ and $\underline{\alpha}=\alpha_{0}-25^{\circ}, i=1,2$. For this problem, $\tau_{1}=0.0005$, $\tau_{2}=0.0106, \tau_{3}=0.0346, \tau_{4}=\tau_{5}=\tau_{6}=\tau_{7}=0.0045$.

Figures 6 and 7 show the open loop and closed loop frequency response of the test system. It can be seen from Fig. 6 that there is a resonance peak in the magnitude response in open loop system and also a sharp drop of the phase angle. The closed loop system shown in Fig 7 has higher damping ratio and smaller overshoot.

\subsection{Controller performance evaluation}

The voltage stability margin is defined as the difference between the operating voltage and the critical voltage. The transient stability margin is given as the difference between the speed after a specified fault duration and the critical speed (CS) of the generator. The critical speed is given by the intersection between the torque-speed curve for the specified 


\section{Bode Diagram}
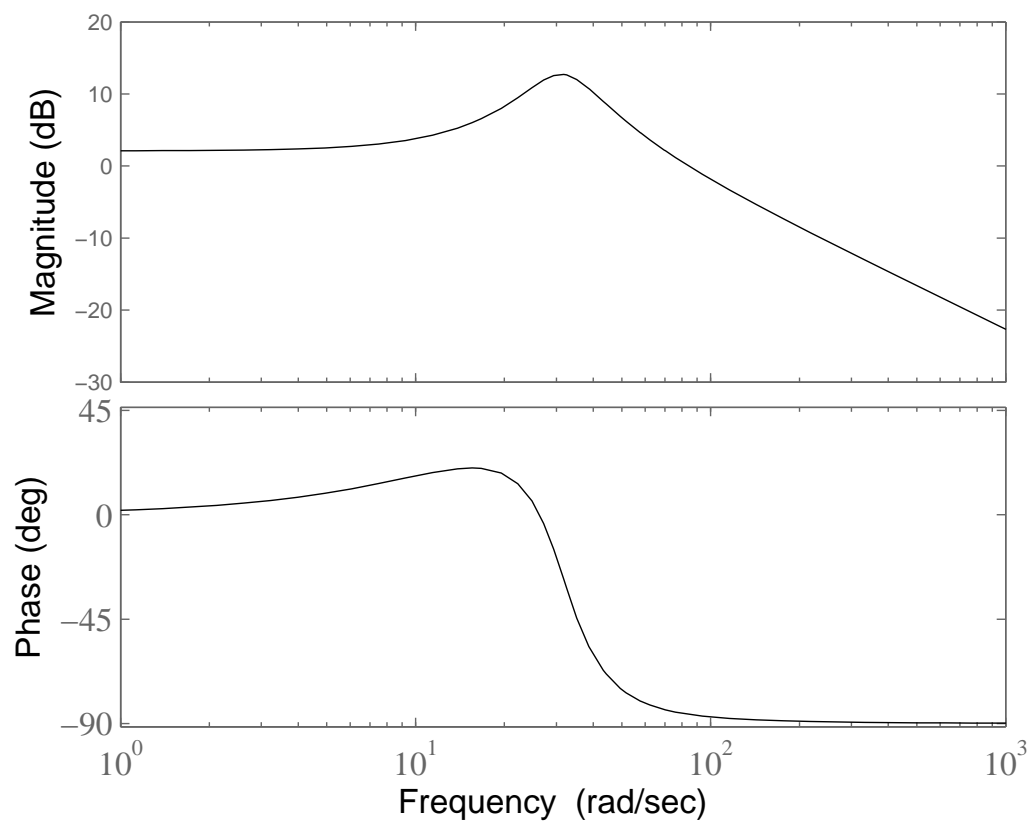

Figure 6: Bode plot of the open loop system.

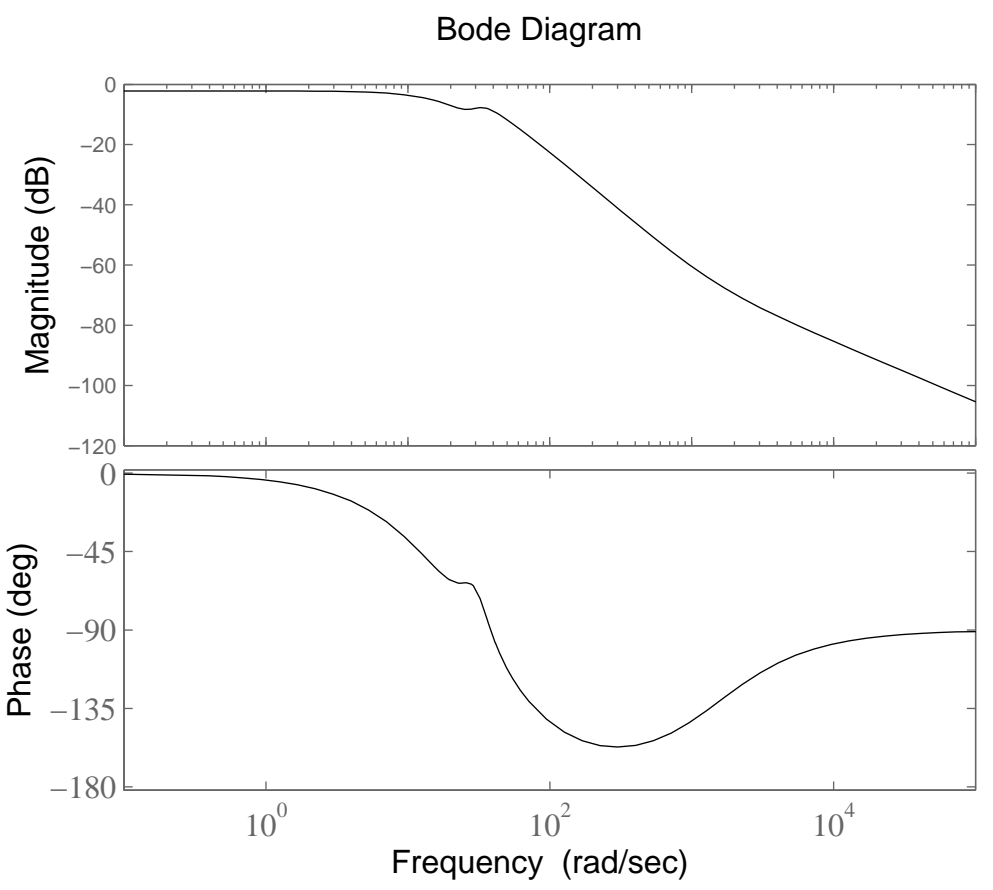

Figure 7: Bode plot of the closed loop system. 
system and the mechanical torque [29]. The critical voltage can be obtained from the P-V curves [30]. The stability analysis of a power system may consider the determination of its critical clearing time (CCT), for a given fault, in order to find the maximum value of the CCT for which the system is still stable. In this paper, the CCT is first estimated by using the following equations and then exact value is determined from simulations in which it is obtained by increasing the fault time interval until the system loses its stability [31].

$$
t_{c}=\frac{1}{T_{m}} 2 H_{m}\left(s_{c}-s_{0}\right),
$$

where $s_{c}$ is the CS of a generator. Different scenarios are simulated to asses the performance of the control of the fixed-speed wind turbine with the proposed STATCOM control.

\subsection{Stability during low voltages}

The performance of the proposed controller for a 100 MVA STATCOM is evaluated for a three phase fault at one of the parallel lines between Bus 6 and Bus 7. The CCT and critical slip CS with the proposed control are $0.18 \mathrm{~s}$ and $0.215 \mathrm{pu}$, respectively. To compare the performance, we also determine CCT and CS with PI based STATCOM, which are $0.165 \mathrm{~s}$ and 0.19 pu. Figs. 8 and 9 show the speed and terminal voltage of induction generator with the PI controller and the proposed controller, respectively.

The fault is applied at $1 \mathrm{~s}$ and cleared at $1.18 \mathrm{~s}$. From Figs. 8 and 9 it is clear that the proposed controller can stabilise the voltage and speed of the induction generator with fault clearing time of $0.18 \mathrm{~s}$. The slip of $0.195 \mathrm{pu}$ at the fault clearing is greater than the critical slip of $0.19 \mathrm{pu}$ as obtained for the PI controller with numerical simulations. Thus with PI controller the speed continues to increase even after the fault is cleared. Furthermore, the voltage gradually decreases and the wind generators have to be disconnected from the grid to protect them and avoid voltage collapse. The designed controller guarantees stability if the system operating point, after the fault is cleared, falls within the region for which the controller is designed. We can conclude that the proposed controller performs better than the PI controller and results in a higher critical clearing time.

\subsection{Turbine response to a change in wind speed}

When the SCIG is subjected to a sudden rise in speed, active and reactive powers increase substantially. By changing the pitch angle and providing an adequate reactive support to 


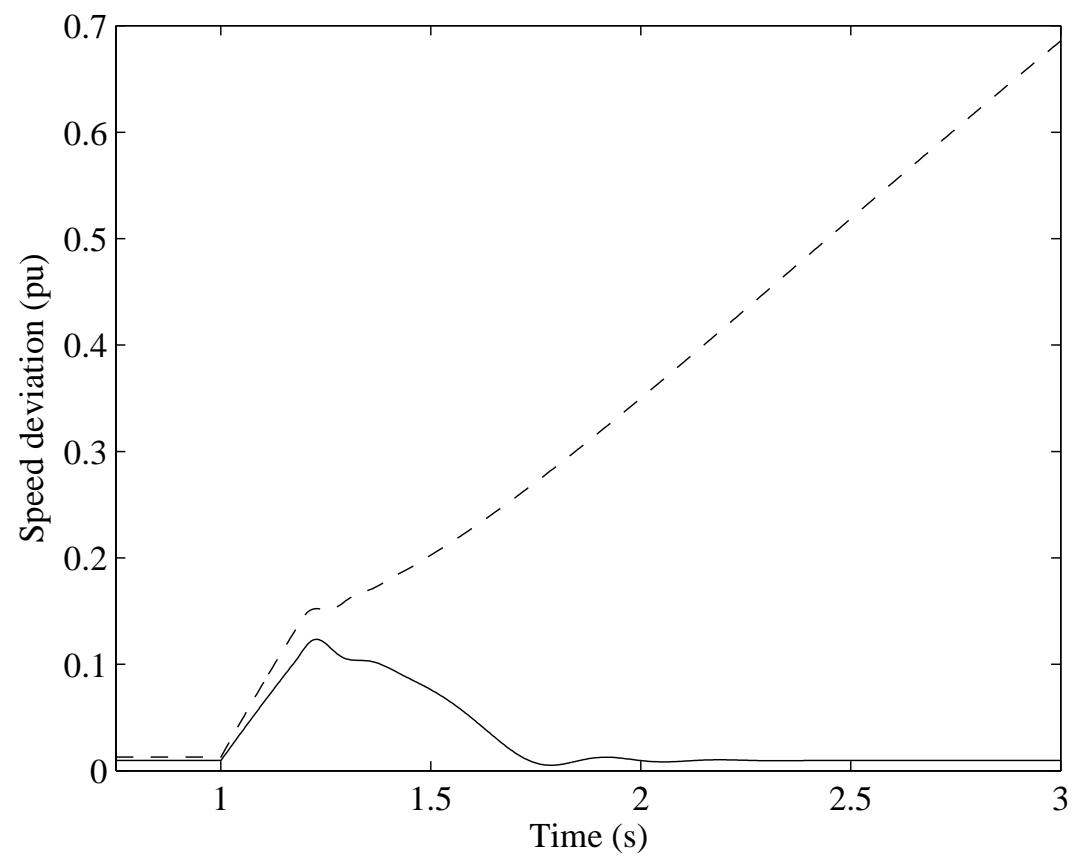

Figure 8: Generator speed for three-phase fault at one of lines 6-7 (Solid line designed and dash line PI controller)

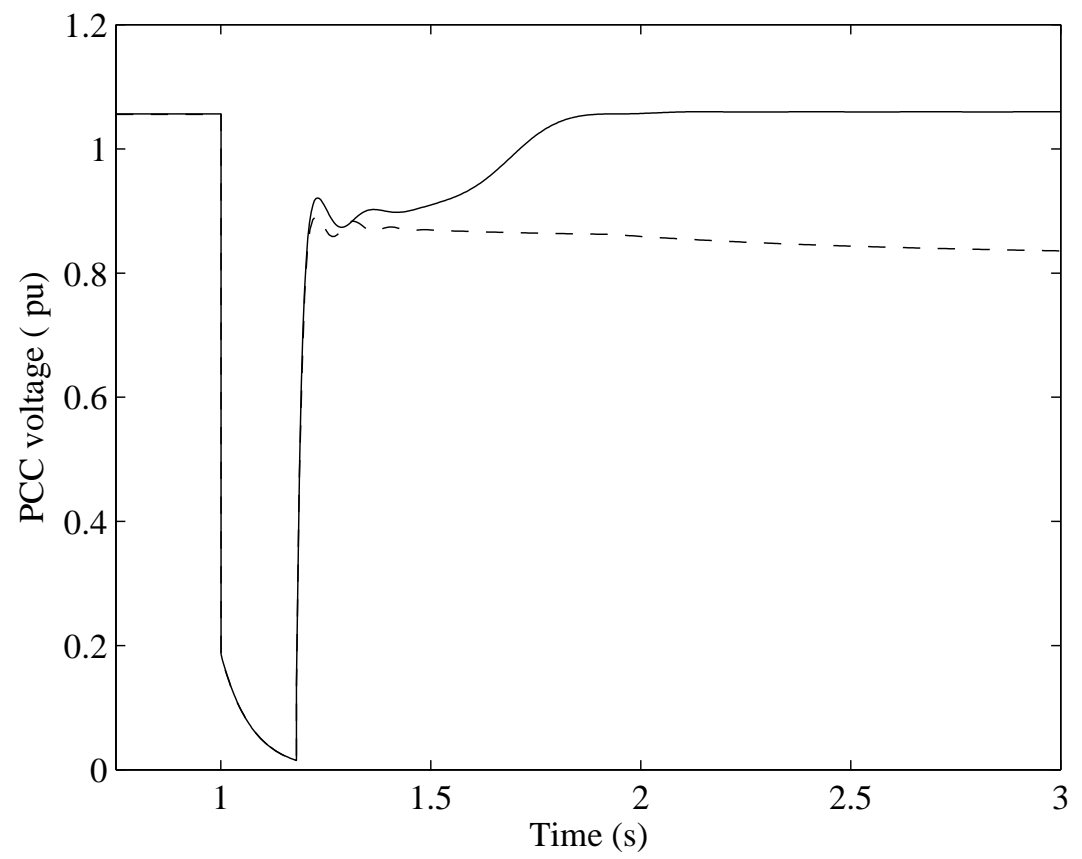

Figure 9: Voltage at bus 4 for for three-phase fault at one of lines 6-7 (Solid line designed and dash line PI controller) 
the system, the proposed control scheme ensures a stable response to these sudden changes in operating conditions related to speed variations and/or faults in the system. To illustrate this stabilising capability of the proposed controller, a simulation in which the initial wind speed applied to each turbine is $8 \mathrm{~m} / \mathrm{s}$ was carried out. The wind speed was then ramped to $9 \mathrm{~m} / \mathrm{s}$ during $1 \mathrm{~s}$, starting at $t=5 \mathrm{~s}$. After that, it was ramped down to $8 \mathrm{~m} / \mathrm{s}$ again during $1 \mathrm{~s}$. Finally, at $t=10 \mathrm{~s}$ a temporary fault was applied at wind farm 1 and cleared after 150 ms. Since the asynchronous machine operates in generator mode, its speed is slightly above the synchronous speed $(1.011 \mathrm{pu})$.

Fig. 10 shows the applied variation of the wind speed, and Figs 11 and 12 show the response to this variation, as well as the subsequent response to the mentioned temporary fault. The generator speed shown in Fig. 12 increases quickly due to the increased aerodynamic torque. The electrical power increases too, until the pitch controller reacts by modifying the pitch angle as shown in Fig. 11. Over that time frame the turbine speed will have increased from $1.0028 \mathrm{pu}$ to $1.0047 \mathrm{pu}$. Initially, the pitch angle of the turbine blades is 8 degree. When the output power exceed rated power, the pitch angle shown in Fig. 13 is increased from 8 deg to $13 \mathrm{deg}$ in order to bring output power back to its nominal value. The designed STATCOM controller increases the reactive power supply to keep the voltage constant which is visible from Fig. 14, while the speed controller prevents the generator speed becoming too high. It can be concluded that the proposed controller performs well in the case of change of input wind speed and severe three-phase fault.

\section{Conclusions}

This paper proposes an advanced control technique for voltage control of a grid connected wind farm and demonstrates its effectiveness. Detailed modeling of each component and a suitable control strategy of STATCOM is presented. The STATCOM controller scheme is based on the reformulation of the nonlinear dynamics of wind generators using the mean-value theorem. The effectiveness of the proposed control scheme is demonstrated on a detailed model of a multi-turbines power system. The designed controller is shown to be very effective under large disturbances. The performance of the proposed STATCOM controller is compared with a PI-based STATCOM and simulation results confirm the efficacy of the proposed controller 


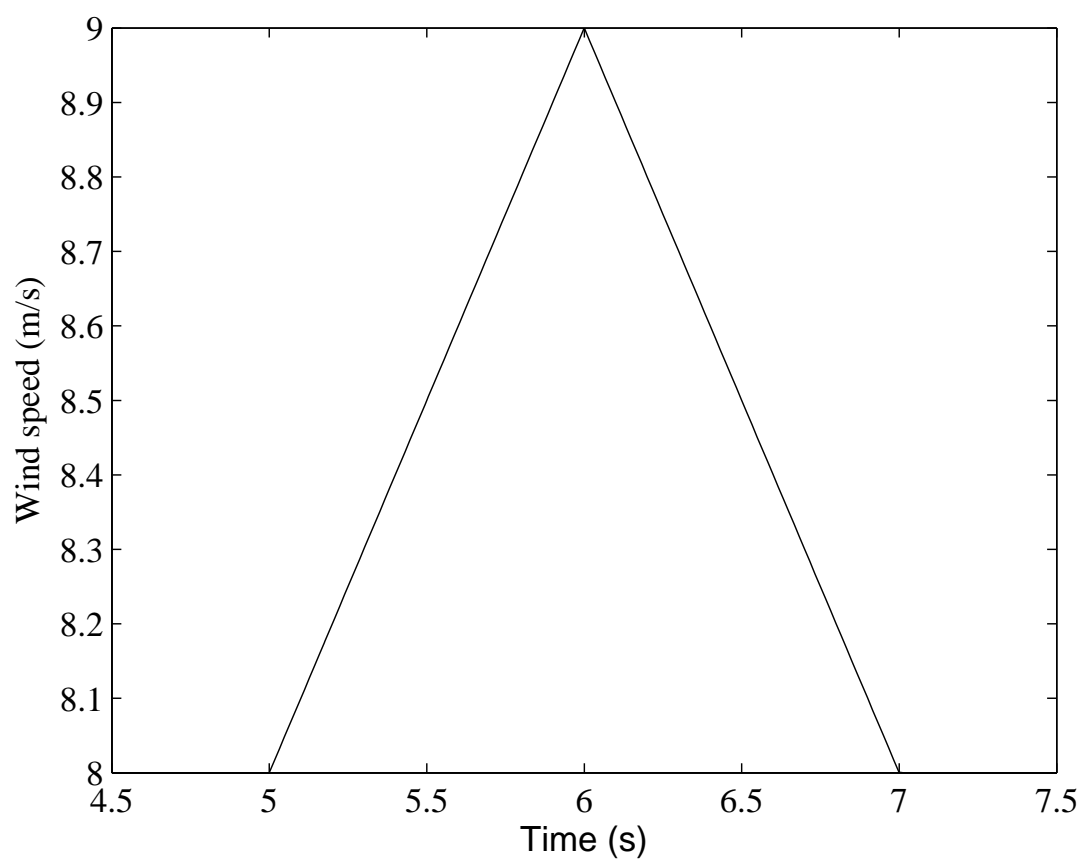

Figure 10: Wind speed

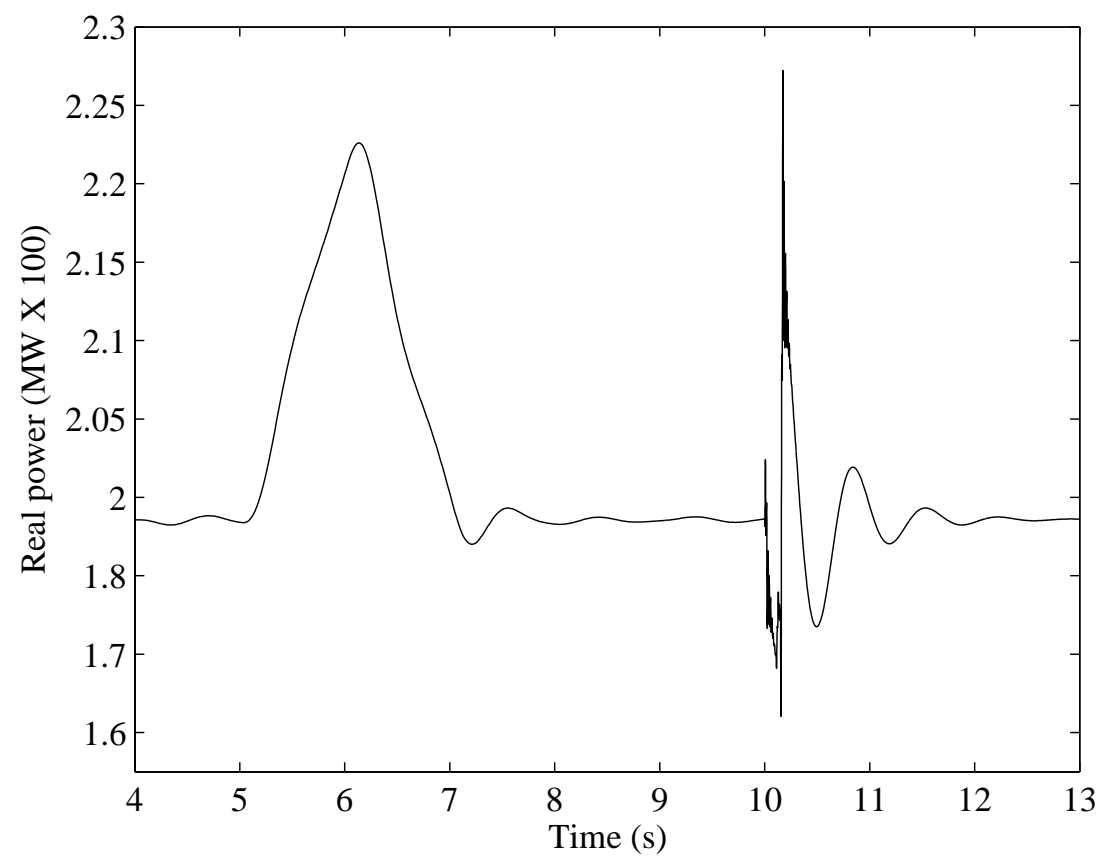

Figure 11: Real power output of wind generator 


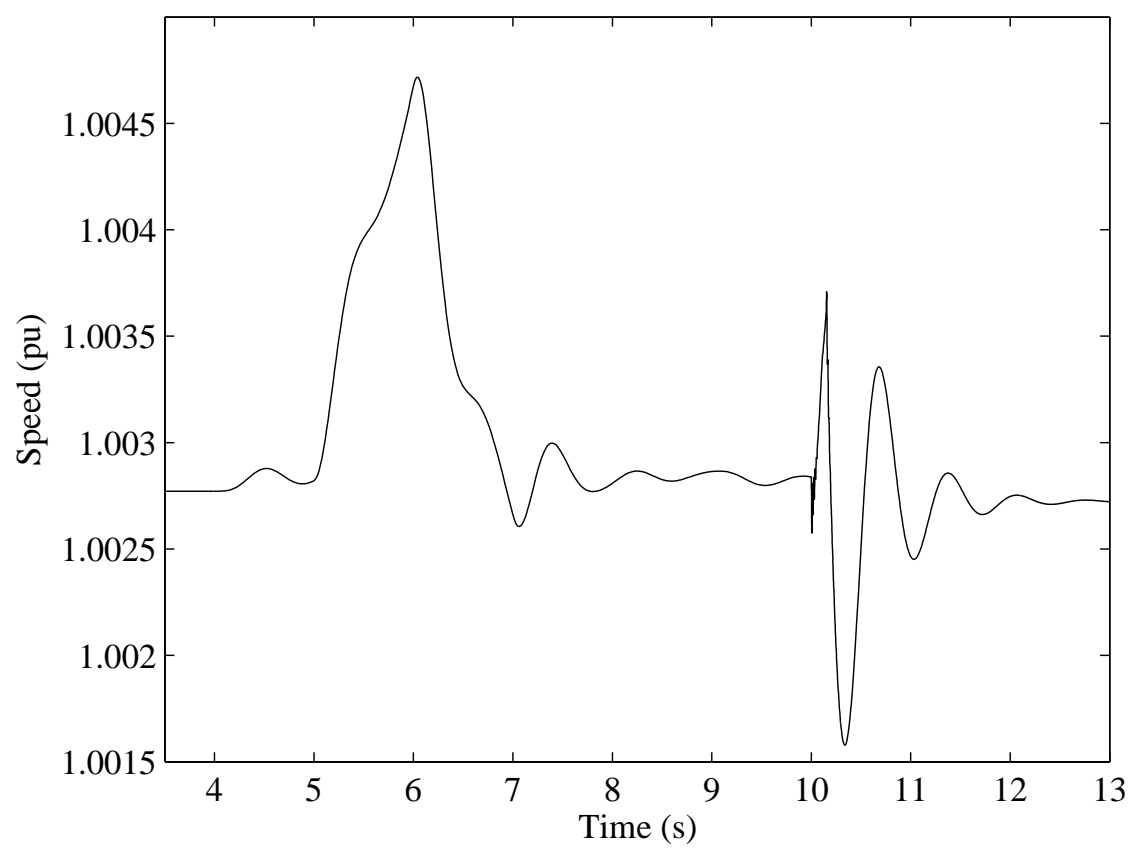

Figure 12: Speed of wind generator

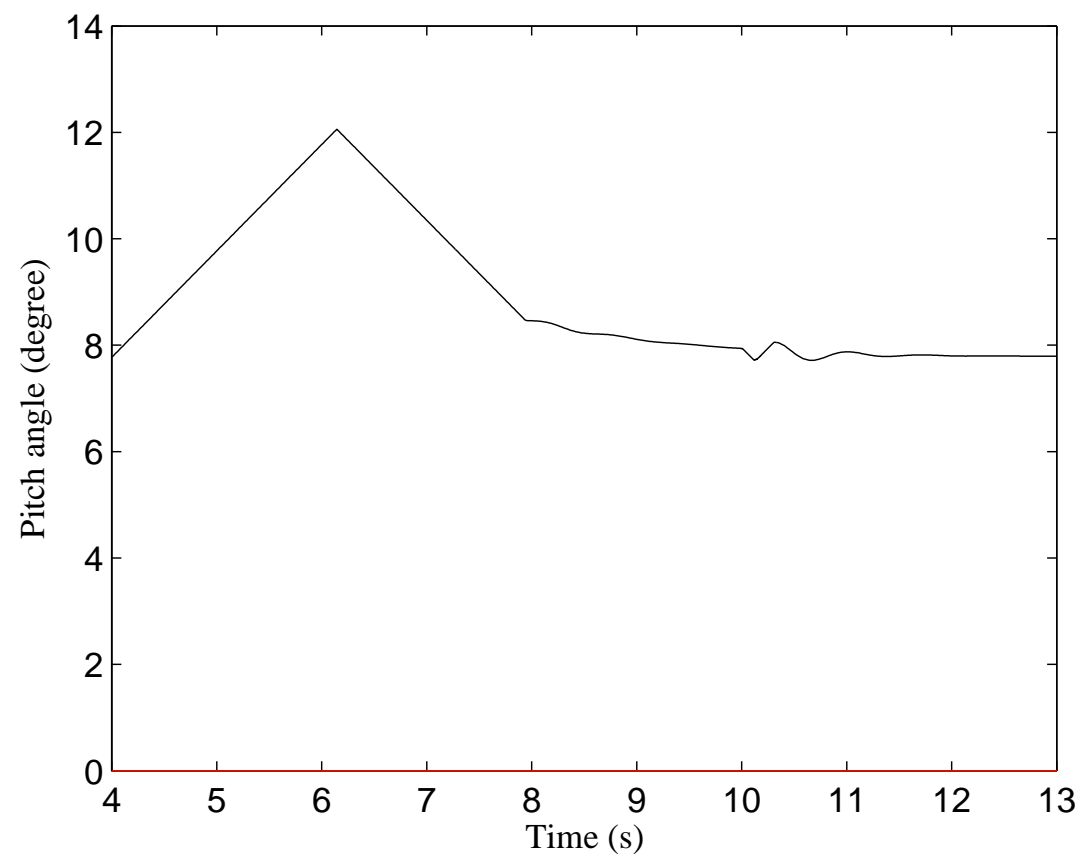

Figure 13: Pitch angle 


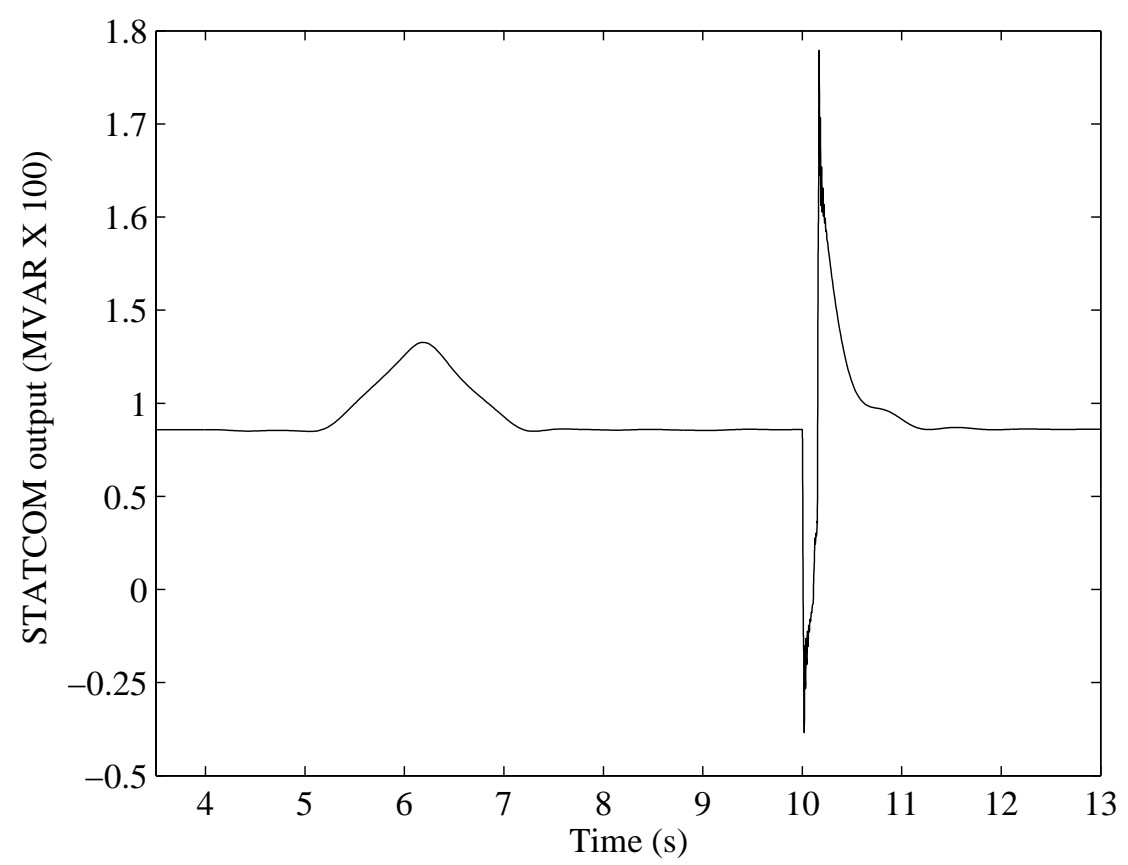

Figure 14: Reactive power output of designed STATCOM controller

over the conventional STATCOM controller. Moreover, the overall voltage control scheme and the control-design methodology developed in this paper can also be applied to larger wind farms and other network configurations.

\section{References}

[1] IEA Wind Energy Annual Report 2005 . International Energy Agency (IEA). Tech. Report; 2006.

[2] Holttinen H, Pedersen J. The effect of large-scale wind power on a thermal system operation. In: Proc. of 4th International Workshop on Large-scale Integration of Wind Power and Transmission Networks for Offshore Wind Farms. Stockholm, Sweden; 2003, p. E1-7.

[3] Johnson GL. Wind Energy Systems. Manhattan: Prentice-Hall; 2004.

[4] Rathi MR, Mohan N. A novel robust low voltage and fault ride through for wind turbine application operating in weak grids. In: 31st Annual Conference of IEEE Industrial Electronics Society. 2005, p. 2481-6. 
[5] EL-Helw HM, Tennakoon SB. Evaluation of the suitability of a fixed speed wind turbine for large scale wind farms considering the new UK grid code. Renewable Energy January 2008;33(1):1-12.

[6] Sun J, Czarkowski D, Zabar Z. Voltage flicker mitigation using PWM-based distribution STATCOM. In: IEEE Power Engineering Society Summer Meeting; vol. 1. 2002, p. 616-21.

[7] Ledesma P, Usaola J. Doubly fed induction generator model for transient stability analysis. IEEE Trans on Energy Conversion June 2005;20(3):388-97.

[8] Nemmour AL, Mehazzem F, Khezzar A, Hacil M, Louze L, Abdessemed R. Advanced backstepping controller for induction generator using multi-scalar machine model for wind power purposes. Renewable Energy October 2010;35(10):2375-80.

[9] Kodama N, Matsuzaka T, Tuchiya K, Arinaga S. Power variation control of a wind generator by using feed forward control. Renewable Energy January-April 1999;16(14):2375-80.

[10] Jurado F, Saenz JR. An adaptive control scheme for biomass-based diesel-wind system. Renewable Energy January 2003;28(1):45-57.

[11] Sakamoto R, Senjyu T, Kaneko T, Urasaki N, Takagi T, Sugimoto S. Output power leveling of wind turbine generator by pitch angle control using $H_{\infty}$ control. Electrical Engineering in Japan 2008;162(4):45-57.

[12] Jauch C, Islam SM, Sorensen P, Jensen BB. Design of a wind turbine pitch angle controller for power system stabilisation. Renewable Energy November 2007;32(14):233449.

[13] Hossain MJ, Pota HR, Ugrinovskii V, Ramos RA. Excitation control for large disturbances in power systems with dynamic loads. In: IEEE Power and Energy Society General Meeting. Calgary, Canada; 2009, p. 1-8. 
[14] Griffo A, Lauria D. Series connected PWM GTO current/source convertor with symmetrical phase angle control. IEE Proceedings B, Electric Power Applications July 1990;137(1):205-12.

[15] Shen C, Yang Z, Crow ML, Atcitty S. Control of STATCOM with energy storage device. In: IEEE Power Engineering Society Winter Meeting; vol. 4. Singapore; 2000, p. 2722-8.

[16] Jauch C, Islam SM, Sorensen P, Jensen BB. Design of a wind turbine pitch angle controller for power system stabilisation. Renewable Energy March 2007;32(14):2334-49.

[17] Hossain MJ, Pota HR, Ugrinovskii V, Ramos RA. Simultaneous statcom and pitch angle control for improved fault ride-through capability of fixed-speed wind turbines. IEEE Trans on Sustainable Energy October 2010;1(3):142-51.

[18] Srithorn P, Sumner M, Yao L, Parashar R. A STATCOM with supercapacitors for enhanced power system stability. In: 4th IET Conference on Power Electronics, Machines and Drives. London; 2008, p. 96-100.

[19] Ackermann T. Wind Power in Power Systems. England: John Wiley and Sons Ltd; 2005.

[20] Abdin ES, Xu W. Control design and dynamic performance analysis of a wind turbineinduction generator unit. IEEE Trans on Energy Conversion March 2000;15(1):91-6.

[21] Nandigam K, Chowdhury BH. Power flow and stability models for induction generators used in wind turbines. In: IEEE Power Engineering Society General Meeting. Denver, CO; 2004, p. 2012-6.

[22] Kundur P. Power System Stability and Control. New York: Mcgraw-Hill; 1994.

[23] Fernandez L, Garcia C, Saenz JR, Jurado F. Equivalent models of wind farms by using aggregated wind turbines and equivalent winds. Energy Conversion and Management March 2009;50(3):691-704.

[24] Khalil HK. Nonlinear Systems. New York: Prentice-Hall; 1992.

[25] Petersen IR, Ugrinovskii VA, Savkin AV. Robust Control Design Using $H_{\infty}$ Methods. London: Springer; 2000. 
[26] Hossain MJ, Pota HR, Ugrinovskii V, Ramos RA. Voltage mode stabilisation in power systems with dynamic loads. International Journal of Electrical Power and Energy Systems November 2010;32(8):911-20.

[27] Savkin AV, Petersen IR. Nonlinear versus linear control in the absolute stabilisability of uncertain linear systems with structured uncertainty. IEEE Trans on Automatic Control January 1995;40(1):122-7.

[28] Moheimani SR, Savkin AV, Petersen IR. A connection between $H_{\infty}$ control and the absolute stabilizability of discrete-time uncertain linear systems. Automatica 1995;31(8):1193-5.

[29] Akhmatov V, Knudsen H, Bruntt M, Nielsen A, Pedersen JK, Poulsen NK. A dynamic stability limit of grid-connected induction generator. In: International Conference on Power and Energy Systems. 2000, p. 235-44.

[30] Cutsem TV, Vournas C. Voltage Stability of Electric Power Systems. Norwell, MA: Kluwer Academic; 1998.

[31] Hemeida AM. Improvement of voltage stability and critical clearing time for multimachine power systems using static var compensator. ICGST-ACSE 2009;9(2):41-7. 